\title{
CYBERBULLYING: IMPORTANT CONSIDERATIONS
}

\author{
Allen D. Truell, Ball State University, atruell@bsu.edu \\ Jensen J. Zhao, Ball State University,jzhao@bsu.edu \\ Edward J. Lazaros, Ball State University, ejlazarous@bsu.edu \\ Christopher Davison, Ball State University, cbdavison@bsu.edu \\ Dakota L. D. Nicley, Ball State University,dlnicley@bsu.edu
}

\begin{abstract}
The purpose of this literature review is multi fold. First, the various interpretations of cyberbullying will be reviewed. Second, statistics related to cyberbullying will be presented. Third, some ways cyberbullying occurs will be discussed. Fourth, individuals and groups most at risk of cyberbullying will be identified. Fifth, the effects of cyberbullying will be debated. Sixth, cyberbullying prevention and intervention strategies will be explored.
\end{abstract}

Keywords: Cyberbullying; Security; Information Systems; Cybervictimization;

\section{INTRODUCTION}

For both youth and adults, information technologies such as cellphones and computers have become commonplace in day-to-day life to keep them connected to friends, communicate, find information, as well as engage and maintain all sorts of activities and hobbies. Unfortunately, threats also exist on the Internet that presents a risk to the social and to emotional dimensions of well-being. One issue that has increasingly become the focus of research over the last decade is cyberbullying. As mentioned by Tankrikulu (2018), with the increase in cyberbullying cases reported worldwide, cyberbullying has become a serious concern due to the asperity of adverse effects it has on an individual.

\section{CYBERBULLYING INTERPRETATIONS}

As explained by Waller, Lokhande, Ekambaram, Deshpande, and Ostermeyer (2018), there is no definite consensus on what constitutes cyberbullying. This lack of consensus has led to numerous interpretations of cyberbullying. Many of the interpretations characterize cyberbullying by intentional, repeated acts of sending aggressive or harmful messages online to a victim with the intent to harass, ridicule or mistreat the target (Callaghan et al., 2015; Fousiani, Dimitropoulou, Michaelides, \& Petegem, 2016; Mehari \& Farrell, 2018; Patchin 2016; Purdy \& McGuckin 2015; Waasdorp \& Bradshaw, 2015; Zaborskis, Ilionsky, Tesler, \& Heinz, 2018). Prior research suggests that the characteristics of cyberbullies overlap with those of traditional bullies (Mehari \& Farrell, 2018; Waller et al., 2018). Cyberbullying is similar to traditional bullying with the added dimension of information technologies. Bullying behaviors facilitated through information technologies provide bullies some level of anonymity. This anonymity can make bullies bolder in what they say when constructing hurtful messages (Patchin, 2016; Tanrikulu, 2018; Waller et al., 2018). Cyberbullying usually takes place online through various avenues of e-communication such as instant messages, e-mails, blogs, social media pages, online games, Internet forums, and chat rooms (Waller et al., 2018).

\section{CYBERBULLYING STATISTICS}

For youth, the percentage of individuals who have reported experiencing cyberbullying throughout their life has grown tremendously in recent years (Mehari \& Farrell, 2018; Patchin, 2016; Waller et al., 2018). Estimates of cyberbullying cases have ranged anywhere from $3 \%$ to $72 \%$ depending on the interpretation and measures of cyberbullying researchers used to gather data. The majority of cyberbullying estimates fall somewhere between $20 \%$ and $40 \%$ (Mehari \& Farrell, 2018; Selkie, Fales \& Moreno, 2016). According to Waller et al. (2018), within a 10-year period from 2006 to 2016, the percentage of people who have been victimized by cyberbullying had almost doubled from 


\section{Issues in Information Systems \\ Volume 20, Issue 2, pp. 83-88, 2019}

$18 \%$ to $34 \%$. Alternatively, other research on cyberbullying has found that $15 \%$ to $41 \%$ of adolescents have been the aggressors, which implies they have committed cyberbullying behaviors at some point in their lifetime (Young, Tully, \& Ramirez, 2017). Patchin (2016) noted that the likelihood of being a cyberbullying victim has nearly doubled among middle and high school students from 19\% to 34\% from 2004 to 2016. Beyazit, Simsek, and Ayhan (2017) suggested that this increase might be due to more time being spent by youth on their phones or computers accessing social media sites.

For youth when analyzed by gender, there are a few differences when it comes to being victims cyberbullying. For instance, adolescent girls are significantly more likely to be victims of cyberbullying than are boys (Patchin, 2016; Waller et al., 2018). That said, boys were significantly more likely to report cyberbullying as well as to cyberbully others. Boys were up to three times more likely to be involved in cyberbullying by sending mean, harassing, or threatening messages to someone they know (Baldry, Farrington, \& Sorrentino, 2016). Both genders are capable of being cyberbullies themselves, as sometimes individuals who are cyberbullied will in-turn cyberbully others to feel better (Patchin, 2016; Waller et al., 2018).

For adults, cyberbullying was found to primarily occur via social media, instant messaging, e-mail, and text-message (Kowalski, Toth, \& Morgan, 2018). When it comes to knowing the cyberbully, Waasdorp \& Bradshaw (2015) found that cyberbullies tend to be individuals known to the victims and may have had a relationship with such as someone they thought was a friend, a colleague/co-worker, or their significant other. Out of a sample of around 28,000 youth surveyed by Waasdorp and Bradshaw (2015), 61.6\% reported receiving harassing messages on social media websites, $39.6 \%$ indicating that it was through an instant message or text message, $15.7 \%$ through an e-mail, $14.2 \%$ that it was through an online game, and 8\% indicated it was another medium that fell outside of these categories. The findings suggest that cyberbullying can occur across multiple Internet-capable devices (Barlett et al., 2017; Beyazit et al., 2017; Waasdorp \& Bradshaw, 2015).

\section{HOW CYBERBULLYING OCCURS}

Fousiani et al. (2016) reported that cyberbullying behaviors are linked to traits such as psychological control, autonomy, relatedness frustration and recognition of human characteristics in bullies. Further, there was a negative correlation to relatedness satisfaction, empathic concern, and recognition of human uniqueness to victims (Fousiani et al., 2016). Barlett \& Fennel (2018) speculated that cyberbullying might be a popular method for bullying because of the anonymity; anyone who has an Internet-capable device can victimize an individual, regardless of the cyberbullies physical stature. The most commonly reported type of cyberbullying amongst youth is reading mean messages posted on social media sites, followed by text messages, instant messages, online gaming, and e-mail (Barlett, Chamberlin, \& Witkower, 2017; Waasdorp \& Bradshaw, 2015). Among youth, daily Internet usage that exceeds three hours puts them more at risk of being cyberbullied (Lee, Hong, Yoon, Peguero, \& Seok, 2018). Cyberbullying generally is a behavior that does not occur on its own, but it is progressed by a complicated relationship between the individual and a multitude of factors that can aggravate the risk (Lee et al., 2018).

Other factors that can influence cyberbullying behaviors are environmental factors. Environmental factors such as cultural, societal values, and social media may play a large part in the appearance of bullying behaviors, which can shape a child's attitudes, behaviors, their relations and socialization with family, friends, neighbors, peers, teachers, and so on (Lee et al., 2018). According to Waller et al. (2018), poor parent-child relationships are associated with an increased risk of cyberbullying behaviors; unsurprisingly, poor parent-child relationships are also tied closely to aggressive behaviors and delinquency. Authoritarian parenting styles were found to increase the risk of cyberbullying and victimization, while authoritative/flexible parenting styles have been found to decrease the risk of cyberbullying and victimization (Waller et al., 2018). This observation suggests that authoritative parenting practices are more effective than the former in successfully reducing the risk of the adolescent being the victim of cyberbullying or being a cyberbully (Waller et al., 2018).

Parents with limited knowledge of the Internet and information technologies generally are not as good at preventing cyberbullying as those who are knowledgeable (Beyazit et al., 2017; Young et al., 2017). As found by Barlett \& Fennel, parents tend to underestimate how long their kids spend on the Internet, as well as cyberbullying perpetuation. Barlett \& Fennel (2018) suggested that parental ignorance positively predicted cyberbullying behaviors. This 


\section{Issues in Information Systems}

Volume 20, Issue 2, pp. 83-88, 2019

reflection infers that parents who are disengaged from their children's' online activity may have a child who is either being cyberbullied or is bullying others. Parents can take steps to help decrease the risk of cyberbullying such as educating themselves on parental controls and nuances of the Internet, monitoring Internet usage, having open discussions their children about how to behave on the Internet especially in situations where cyberbullying may occur, and setting time limits on computer usage (Barlett \& Fennell, 2018). Parents must find a line of trust between needing to know what their children are doing while also not imposing too many rules.

Workplace cyberbullying primarily occurs over social networking sites, cellular devices connected to the Internet, IM, and e-mail (Kowalski et al., 2018). Many workplaces are equipped with computers or some Internet-capable communication technology that allows for cyberbullying to occur during the workday. Kowalski et al. (2018) found that colleagues are the most significant perpetrators of cyberbullying in the workplace. Within this group, co-workers at the same level were found to be the most significant perpetrators of cyberbullying, followed by superiors and bosses and then subordinates. To help reduce the adverse effects of cyberbullying, employers should make an effort to ensure that employees understand the consequences of both traditional bullying and cyberbullying in the workplace (Kowalski et al., 2018).

\section{WHO IS AT RISK FOR CYBERBULLYING}

Baldry et al. (2016) reported that as soon as individuals start using the Internet or Internet-capable devices to communicate and interact, they are at risk of becoming targets of cyberbullying. As Lee et al. (2018) suggested, the risk of cyberbullying might increase the longer people stay online. This risk increase may be due to people not understanding the dangers of posting information online (Lee et al., 2018; Van Hee et al., 2018). Social media sites like Facebook and Twitter are convenient places to cyberbully because of the anonymity, availability, and reach provided. Other users may have access to personal information if privacy settings are not established.

Individuals in minority groups have an increased risk of experiencing cyberbullying (Waller et al., 2018). Adolescent girls are more likely to report having experienced cyberbullying than males (Callaghan et al., 2015; Waasdorp \& Bradshaw, 2015; Waller et al., 2018). This higher likelihood may be due to the amount of time girls spend on their cellphone or computer (Waasdorp \& Bradshaw, 2015). Beltran-Catalan, Zych, Ortega-Ruiz, \& Llorent (2018) found that victims of traditional bullying have a higher chance of being victims of cyberbullying as well when compared to adolescents who did not experience traditional bullying. If individuals are being cyberbullied, there is a good chance that they are also physically bullied (Waasdorp \& Bradshaw, 2015). Family conflict is another risk factor for cyberbullying, along with other anti-social or deviant behaviors later in life (Hemphill, Kotevski, \& Heerde, 2015). Individuals who come from dysfunctional families characterized by abusive relationships from the parents are at a higher risk for being bullies, substance abuse, self-harm depression, and a slew of other adverse outcomes that are linked to the severities within the home (Hemphill et al., 2015; Waller et al., 2018).

\section{EFFECTS OF CYBERBULLYING}

The effects of cyberbullying vary depending on how resilient individuals are to its adverse effects. Prior literature on cyberbullying has found an array of different effects cyberbullying can have on a victim ranging from minor anxiety and depression, conduct problems, cyberbully perpetrating, and suicide (Beltran-Catalan et al., 2018; Callaghan et al., 2015; Lee et al., 2018; Geel, Vedder, \& Tanilon, 2014; Hemphill et al., 2015; Mehari \& Farrell, 2018; Patchin, 2016; Patchin \& Hinduja, 2017; Selkie et al., 2016; Tanrikulu, 2018; Waasdorp \& Bradshaw, 2015; Waller et al., 2018, Zaborskis et al., 2018). Comparing victims of cyberbullying to those who are not, individuals who are bullied have a significantly higher risk for depression, low-life satisfaction, and suicidal thoughts and attempts (Geel, Vedder, \& Tanilon, 2014; Mehari \& Farrell, 2018; Zaborskis et al., 2018). Callaghan et al. (2015) found that children who were victims of bullying (cyberbullying included) were more likely to report poor health and low-life satisfaction. Adults can become at risk for depression and anxiety (Waasdorp \& Bradshaw, 2015), but are much less at risk for suicidal ideation than children. Additionally, those who experienced traditional bullying and cyberbullying were more likely to report engaging in risk-taking behaviors.

Much of the literature on cyberbullying suggests that it can negatively influence social relationships, self-esteem, anxiety, loneliness, somatization, sadness, fear, psychoticism, and many other facets of life (Beyazit et al., 2017; 


\section{Issues in Information Systems}

Volume 20, Issue 2, pp. 83-88, 2019

Callaghan et al., 2015; Mehari \& Farrell, 2018; Selkie et al., 2016; Waasdorp \& Bradshaw, 2015; Zaborskis et al., 2018). For boys, being a victim of cyberbullying may decrease life satisfaction. For girls, being a victim of cyberbullying may prompt mental health problems (Callaghan et al., 2015). Cyberbullying is more often than traditional bullying connected to suicidal thoughts. This connection is very concerning given how easy it is for cyberbullies to reach their victims (Geel, Vedder, \& Tanilon, 2014). Individuals who experience cyberbullying are also at an increased risk to inflict self-harm or self-bully (Patchin \& Hinduja, 2016). Findings from Patchin and Hinduja (2015) speculate that victims of cyberbullying were about 12 times as likely to be cyberbullies themselves. Findings from Zaborskis et al. (2018) suggest that it may not be cyberbullying that leads to suicide, but rather cyberbullying in addition to other mental health issues. Other underlying mental health problems such as depression, loneliness, stress, substance abuse issues, and so on can be stimulated by cyberbullying and ultimately affect the risk of suicide (Callaghan et al., 2015; Zaborskis et al., 2018).

\section{CYBERBULLYING PREVENTION/INTERVENTION STRATEGIES}

Prior research on cyberbullying has uncovered a variety of different strategies that have had success in its prevention (Beltrain-Catalan et al., 2018; Beyazit et al., 2017; Cross et al., 2016; Lee et al., 2018; Tanrikulu, 2018; Van Hee et al., 2018; Waller et al., 2018). For example, Van Hee et al. (2018) created an online dictionary that can detect words that are suggestive of cyberbullying that works on social media platforms. Their dictionary can pick up a wide range of cyberbullying behavior. Prevention of cyberbullying requires action from the individual, parents, schools, places of work, and the wider community (Cross et al., 2016). As inferred by Beltrain-Catalan et al. (2018) and Hemphill et al. (2015), effective intervention programs need to be multi-fated and focus on long-term solutions to both the propagation, behavioral, and mental effects traditional and cyberbullying in order to get the most out of them. Multifaceted programs can affect the victim, families, peers, schools, and communities. The responsibility for primary prevention strategies falls on families, workplaces, and schools to combat the risk of cyberbullying amongst youth because they are a strong influence within an individual's microsystem.

Cyberbullying is a unique issue to tackle for schools because various school districts may use different approaches in addressing the issue. In their interviews with school administrators, Young et al., (2017) found schools take action when cyberbullying affects student's school performance, while others will not act until there is a physical altercation on school grounds. This variation in prevention strategies is primarily because administrators try to find a line in what is considered to be an appropriate response that is within their schools' jurisdiction. Since cyberbullying occurs mostly outside of school grounds, certain factors can advance or hinder the response a school takes (Young et al., 2017). There is an array of technological and non-technological prevention/intervention strategies that have been launched over the last decade to help reduce cyberbullying and improve children's cyber safety. A few examples of strategies found to impact cyberbullying reports include strategies such as: ConRed, Cyber-friendly school programs (CFSP), KiVa, Media Heroes, Non au Harcèlement, NoTrap, and ViSC social competence programs (Cross et al., 2016; Tanrikulu, 2018; Van Hee et al., 2018).

Cross et al. (2016) suggest that quality teacher training is vital to the effectiveness of these programs. Some prevention and intervention strategies may take up a good portion of classroom time, so teachers need to be organized and have a plan in place. Teachers block out enough time to cover the material so that they are not having difficulties juggling regular teaching time and cyberbullying prevention. Additionally, many school districts limit technology use during school hours and have a policy in place to confiscate phones or electronic devices used in school. Lee et al. (2018) suggested asking students to keep phones put away during school house or by allowing use only outside of class time. Schools may also block access to social media and other sites not used for educational purposes. While these policies may not have been directly intended to address cyberbullying, they do reduce cyberbullying opportunities during school hours (Young et al., 2017).

Parents need to be aware of what their children are doing online; children need to be open with their parents about if they are being cyberbullied. Barlett \& Fennel (2018) suggest that parents should have an honest discussion with their children about rules for browsing the Internet and how to behave online. Parents of children who are cyberbullies should not to reinforce or contribute to their child's cyberbullying behavior (Beyazit et al., 2017; Young et al., 2017). Parents should check up on their children and be aware of what their children are doing, findings by Barlett and Fennel (2018) suggested that even little actions like parental hovering are negatively correlated to cyberbullying perpetuation 


\section{Issues in Information Systems}

Volume 20, Issue 2, pp. 83-88, 2019

in children. Parents have the responsibility to understand the risks of the Internet and make themselves familiar with using newer technology in order to provide support to their children. As suggested by Beyazir, Simsek, and Ayhan, (2017), parents who do not understand the Internet and information technologies cannot prevent cyberbullying as effectively as those who do. Researchers question whether parents enable cyberbullying among younger students by allowing them the freedom to have a Facebook, Twitter, or other social media account at a young age (Young et al., 2017).

\section{SUMMARY}

The purpose of this paper was multi fold. First, the various interpretations of cyberbullying were reviewed. Second, statistics related to cyberbullying were presented. Third, some ways cyberbullying occurs were discussed. Fourth, individuals and groups most at risk of cyberbullying were identified. Fifth, the effects of cyberbullying were discussed. Sixth, prevention and intervention strategies were explored.

\section{REFERENCES}

Baldry, C. A., Farrington, P. D., \& Sorrentino, A. (2016). Cyberbullying in youth: A pattern of disruptive behaviour. Psicología Educativa, 22(1), 19 - 26.

Barlett, P. C., Chamberlin, K., \& Witkower, Z. (2017). Predicting cyberbullying perpetration in emerging adults: A theoretical test of the Barlett Gentile Cyberbullying Model. Aggressive Behavior, 43(2), 147 - 154.

Barlett, P. C., \& Fennel, M. (2018). Examining the relation between parental ignorance and youths' cyberbullying perpetration. Psychology of Popular Media Culture, 7(4), 547 - 560.

Beltran-Catalan, M., Zych, I., Ortega-Ruiz, R., \& Llorent, J. V. (2018). Victimization through bullying and cyberbullying: Emotional intelligence, severity of victimization and technology use in different types of victims. Psicothema, 30(2), $183-188$.

Beyazit, U., Simsek, S., \& Ayhan, B. A. (2017). An examination of the predictive factors of cyberbullying in adolescents. Social Behavior and Personality, 45(9), $1511-1522$.

Callaghan M., Kelly, C., \& Molcho, M. (2015). Exploring traditional and cyberbullying among Irish adolescents. International Journal of Public Health, 60(2), 199 - 206.

Calvo-Morata, A., Rotaru, C. D., Alonso-Fernandez, C., Freire, M., Martinez-Ortiz, I., \& Fernandez-Manjon, B. (2018). Validation of a cyberbullying serious game using game analytics. IEEE Transactions on Learning, doi 10.1109/TLT.2018.2879354.

Cross, D., Shaw, T., Hawden, K., Cardoso, P., Slee, P., Roberts, C., Thomas, L., \& Barnes, A. (2016). Longitudinal impact of the Cyber Friendly Schools program on adolescents' cyberbullying behavior. Aggressive Behavior, 42(2), $166-180$.

Geel, M., Vedder, P., Tanilon, J. Relationship between peer victimization, cyberbullying, and suicide in children and adolescents. The Journal of the American Medical Association, 168(5), 435-442.

Hempill, A. S., Kotevski, A., \& Heerde, A. J. (2015). Longitudinal associations between cyber-bullying perpetration and victimization and problem behavior and mental health problems in young Australians. International Journal of Public Health, 60(2), 227 - 237.

Kowalski, M. R., Toth, A., \& Morgan, M. (2018). Bullying and cyberbullying in adulthood and the workplace. The Journal of Social Psychology, 158(1), $64-81$.

Lee, M. J., Hong, S. J., Yoon, J. Peguero, A. A., \& Seok, J. H. (2018). Correlates of adolescent cyberbullying in South Korea in multiple contexts: A review of the literature and implications for research and school practice. Deviant Behavior, 39(3), 293 - 308. 
Mehari, R. K., \& Farrell, D. A. (2018). Where does cyberbullying fit? A comparison of competing models of adolescent aggression. Psychology of Violence, 8(1), $31-42$.

Patchin, W. J. (2016). Summary of Our Cyberbullying Research (2004-2016). Retrieved from https://cyberbullying.org/summary-of-our-cyberbullying-research.

Patchin, W. J. (2016). 2016 Cyberbullying Data. Retrieved from https://cyberbullying.org/2016-cyberbullying-data.

Patchin, W. J., \& Hinduja, S. (2017). Digital self-harm among adolescents. Journal of Adolescent Health, 61(6), $761-766$.

Purdy, N., \& Mc Guckin, C. (2015). Cyberbullying, schools, and the law: A comparative study in Northern Ireland and the Republic of Ireland. Educational Research, 57(4), 420 - 436.

Selkie, M. E., Fales, L. J., \& Moreno, A. M. (2016). Cyberbullying prevalence among US middle and high school-aged adolescents: A systematic review and quality assessment. Journal of Adolescent Health, $58(2), 125-133$.

Tanrikulu, I. (2018). Cyberbullying prevention and intervention programs in schools: A systematic review. School Psychology International, 39(1), 74 - 91.

Van Hee. C., Jacobs, G., Emmery, C., Desmet, B., Lefever, E., Verhoeven, B., De Pauw, G. Daelemans, W., \& Hoste, V. (2018). Automatic detection of cyberbullying in social media text. PLoS ONE, 13(10), $1-22$.

Waasdorp, E. T., \& Bradshaw, P. C. (2015). The overlap between cyberbullying and traditional bullying. Journal of Adolescent Health, 56(5), $483-488$.

Waller, P. A., Lokhande, P. A., Ekambaram, V., Deshpande, N. S., \& Ostermeyer, B. (2018). Cyberbullying: An unceasing threat in today's digitalized world. Psychiatric Annals, 48(9), $408-415$.

Young, R., Tully, M., \& Ramirez, M. (2017). School administrator perceptions of cyberbullying facilitators and barriers to preventive action: A qualitative study. Health Education \& Behavior, 44(3), 476 - 484.

Zaborskis, A., Ilionsky, G., Tesler, R., \& Heinz, A. (2018). The association between cyberbullying, school bullying, and suicidality among adolescents: Findings from the cross-national study HBSC in Israel, Lithuania, and Luxembourg. Crisis: The Journal of Crisis Intervention and Suicide Prevention. Advanced online publication. http://dx.doi.org/10.1027/0227-5910/a000536. 